\title{
Language Attitudes Toward Global Englishes Among Thai Undergraduate Students
}

\author{
Denchai Prabjandee ${ }^{1^{*}} \quad$ Punwalai Kewara ${ }^{2 *} \quad$ Rui $\mathrm{Zhu}^{3}$ \\ 1.Department of International Graduate Studies, Faculty of Education, Burapha University, Thailand \\ *E-mail of the corresponding author: denchai@go.buu.ac.th \\ 2.Department of International Graduate Studies, Faculty of Education, Burapha University, Thailand \\ *E-mail of the corresponding author: punwalai@go.buu.ac.th \\ 3.Faculty of Education, Department of International Graduate Studies in Human Resource Development, \\ Burapha University, Thailand E-mail: schreiberpanzer2017@gmail.com
}

\begin{abstract}
The purposes of the study were to investigate the participants' language attitudes toward Global Englishes among 330 undergraduate students from the two different faculties at a university in the eastern part of Thailand. It also compared statistically different students' attitudes toward Global Englishes between males and females, students' different majors, students' different IE (International Experience), and different students' parents' English ability. A questionnaire was used to collect the data, consisting of two sections: 1). Student's demographic data; 2). Attitudes of Undergraduate Students toward Global Englishes. The second section was divided into three components: affective, behavioral, and cognitive. The findings revealed that the Thai undergraduate students held medium attitudes toward Global Englishes and they had an inclination to keep open minds about accepting, speaking and using English or varieties of English; they did not have different attitudes toward Global Englishes between males and females. Also the results indicated that the participants from different majors not only had different beliefs and thoughts about Global Englishes, but they also had different inclination to speak and use English or varieties of English. Moreover, the results revealed that the participants whose general knowledge about English or varieties of English had been affected by their international experience more or less; and the participants whose emotional or feeling segment of language attitudes was related to their parents' English ability.
\end{abstract}

Keywords: language attitudes, Global Englishes, undergraduate students

DOI: $10.7176 / \mathrm{JEP} / 11-33-04$

Publication date: November $30^{\text {th }} 2020$

\section{Introduction}

With the British colonial in the world, the British as "advanced" by learning their language to follow and then tried to assimilate into this "advanced" culture, so some people say that English is the international cultural imperialism (Crystal, 2003). Under the influences of former British Empire and the political or economic power of the USA after the World War II, English nowadays is used in a lot of areas around the world. Once called as the "sun-never set country" in the $19^{\text {th }}$ country, the British Empire owned about one forth land and population of the world. At that time, the language of the ruler, English, was the chosen one for communication between different colonies within the Empire. However, the power started shifting from British Empire to the USA during World War II as the USA became the armory of the whole free world. After World War II, the USA successfully grabbed the opportunity to become the super power of the world, so did the American English, while the European and Asian countries worked hard to recover from the war. English now is the official language for more than eighty countries and becoming the most favorite language in international communication (Phillipson, 2007).

With the economic globalization, English is popular in many fields, such as academy, international political meetings, entertainment, business, and even personal social interaction (Buck, 2005). In the field of mass media, English is the most favorite working language. Take TV news as an example. CNN and BBC are good choices to get information about the current international news. In the entertainment industry, English has an unparalleled position. In the movie field, Hollywood plays an important role and produces lots of movies every year. Among them, most are in English or with English subtitles. In the music field, having English communication ability seems to be the basic prerequisite for the artists to compete in the world market. The reason of choosing English is mainly due to its wide acceptability (Melchers \& Shaw, 2011).

Among all the academic papers published every year, at least half of them are written in English, and the number of these papers are still on the rise year after year (Galloway and Rose, 2015). Besides being used in books, newspaper, academic conferences, science technology, etc., English is also the main language employed in international settings. For instance, in international airports, English signals are almost everywhere. And within most international organizations, such as UN, GATT, NATO, IMF, ASEAN, etc., English is usually the first language when people want to interact with others who have different mother languages (Cheshire, 1991). From above the cases, English becomes the international Lingual Franca. As a Lingual Franca, English influences many people's language choices and the way of thinking as well. English-globalization movement has been the transition 
from the horizontal expansion to horizontal expansion and vertical depth of combining state and then gave birth to the hegemony of the English language (Seidholfer, 2011).

\section{Statement of Problems}

Just like every coin has two sides, so does the globalization of English as if it is a double-edged sword. Crystal (2003) pointed out that "Perhaps the presence of a global language will make people lazy about learning other languages, or reduce their opportunities to do so. Perhaps a global language will hasten the disappearance of minority languages, or - the ultimate threat - make all other languages unnecessary" (p. 15). This observation echoed with Melitz (2007), stating that English globalization may bring threats to the existence of local languages. Some languages may have limited space for development which later might result in extinction (Jenkins, 2003). Following the extinction is the loss of cultural identity and integrity (Jenkins, 2007). Further, Crystal (2003) also pointed out that as the speakers chose English for daily communication, their native languages would be restricted in development and would possibly be abandoned.

As English is increasingly used for global communication in multilingual context these days, Native English Speakers (NES) are in the minority in contrast to the rising number of Non-native English Speakers (NNES) (Galloway and Rose, 2015). However, despite the changing demographics of English speakers around the globe, the NES episteme still dominates in English Language Teaching (ELT), evident in the continued use of native norm English as a yardstick of competence (Galloway, 2013). A number of pedagogical proposals have been put forward for change in ELT practice in relation to the globalization of English. These proposals contend for the necessity to expose English learners to the diversity of English (Matsuda, 2002, 2012a, b; Matsuda \& Friedrich, 2012) and raise their awareness of multilingualism and issues related to the spread of English (Dewey, 2012; McKay, 2002, 2009, 2012).

In order to support such proposals, it is important to examine learners' attitudes towards the global spread English, or Global Englishes (Galloway, 2013). Such exploration will be able to help teachers understand learners' readiness to undertake a changing journey of learning English, where it has multiple forms. In addition, it was deemed important to investigate learners' attitudes because they are one of the main stakeholders in ELT, in order to gain a deeper understanding and to think critically about English education since curriculum change should not be made prematurely without considering learners' attitudes.

Many studies have investigated learners' attitudes towards Global Englishes (e.g., Matsuda, 2000; Wei, 2016), yet there is the scarcity of research in Thailand context. Hayes (2014) pointed out that Thai students subscribed to the notion of English as a tool for personal advancement nut that position of Thai as the language of national identity remains unchallenged. English is thus perceived as an essential lingua franca which links Thailand culturally, intellectually and commercially with other ASEAN countries and the rest of the world. Indeed, English is increasingly referred to as the lingua franca in the Thai setting (Baker, 2008; 2009; Foley, 2007; Kirkpatrick, 2010). As seen in prior research, according to Matsuda (2000) interpreted attitudes as three components which are affective, conative and cognitive; the studies were conducted in many contexts, but little is known what attitudes of English learners hold about Global Englishes in Thailand.

Additionally, it is obvious that little evidence has compared the different attitudes towards Global Englishes between the students with an English major at FH (Faculty of Humanities and Social Sciences) and the students studying at International College. These two groups have distinct characteristics, and it is worthwhile to compare. The students who came from the program in English Language in the Department of Western Languages at FH, and their language skills including listening, speaking, reading and writing were emphasized. International College students who studied and used English as a medium of instruction. Even though the students who studied all the courses in English, due to the different faculty atmosphere, environment and academic activities, they might have different awareness and understanding about English globalization, and these elements may lead to their different attitudes toward Global Englishes.

For these reasons, the study was intended to bridge the gap between theory and practice in a Thai context by investigating the learners' attitudes toward Global Englishes in relation to ELT courses, offered insights into what Global Englishes perspectives of ELF undergraduate students would look like, as well the possible influence it may have on attitudes. That being said, this study aimed to generate a better understanding of the students' attitudes toward Global Englishes, their preferences for varieties of English were reflections of what they believed as models that they wanted to learn and use. Also this study tried to help relevant people involved in ELT to reflect on the significance of linguistic diversity that had emerged as a common sociolinguistic phenomenon in international context, and saw the exposure of varieties of English as relevant approaches, with five specific research questions (RQ), as follows:

1. What were the students' attitudes toward Global Englishes?

2. Were there any statistically different students' attitudes toward Global Englishes between males and females?

3. Were there any statistically different attitudes toward Global Englishes between Faculty of Humanities and Social Sciences (FH) and International College (IC) students? 
4. Were there any statistically different attitudes toward Global Englishes between students who had international experience and those who did not have?

5. Were there any statistically different attitudes toward Global Englishes between the students whose parents can speak English and those who cannot?

\section{Literature review}

\subsection{Undergraduate students}

In this study, according to different academic requirements, undergraduate students were those who studied relevant subjects in English from the two faculties at a University in the eastern part of Thailand. Some students came from the program in English Language in the Department of Western Languages at Faculty of Humanities and Social Sciences, and their language skills including listening, speaking, reading and writing were emphasized. Other students came from International College, they studied and used English as a medium of instruction (e.g. IBM (International Business Management), Marketing, HRD (Communication Skill for Human Resource Development), GB (Global Business Communication), etc.). The relevant studies included all the academic programs up to the level of a bachelor's degree.

\subsection{English Language Teaching (ELT)}

Indeed, 'ELT' is not the only name given to the field as a whole - we might also encounter 'EFL' (incorporated into the International Association of Teachers of English as a Foreign Language, that is, LATEFL); 'ESL' (English as a Second Language); and 'TESOL' (both an umbrella term for teaching English to Speaker of Other Languages and the name of TESOL International Association for teachers) (G. Hall, 2016).

As Howatt and Widdowson (2004) note, establishing the origins of terminology and expressions is a 'a needle-in-a-haystack task with few clear-cut answers', yet the use of one term rather than another can reflect a particular perspective on the field and its development. Thus, as English in the $21^{\text {st }}$ century is no longer a single entity and has multiple forms and is increasingly a lingua franca in conversations between those who do not share a first language, 'English as a Foreign language' no longer seems to capture the scope of English and English language teaching in the contemporary world. Similarly, the now widespread recognition of the importance of bilingualism and multilingualism for individual and societal language use suggests that English will not be the second language of a substantial number of learners around the world.

\subsection{Global Englishes}

Crystal (2003) pointed out that the global spread of English is a process which set into motion and currently being influenced by colonialism, imperialism, capitalism, neoliberalism, popular culture, technological advancements, and so on. The situation has complicated a number of linguistic issues and cultural phenomena. This study adopted the theory of Galloway and Rose (2015) define that Global Englishes includes the concepts of World Englishes, which focuses on the identification and codification of national varieties of English, and ELF, which examines English within and, across the borders, as well as focusing on the global consequences of English's use as a world language. Global Englishes extends the lens of these fields to incorporate many peripheral issues associated with English, such as globalization, linguistic imperialism, education, language policy and planning.

\subsection{Language attitudes}

Language attitude in this study was derived from Garret's study (2010), who divided language attitudes in three components: affective, behavioral and cognitive. With regard to language attitudes, the components were explained as follows:

1. Affective component concerned the emotional and feeling segment toward a language. Additionally, it was related to the statement which affected a conscious mental reaction in another person, also subjectively dealt with the response or aspect of consciousness that were brought to the surface about something.

2. Behavioral component referred to an intention of the plan of an action. Furthermore, it meant a person's tendencies to behave in a particular way toward a language, also referred to that part of attitude which represented a commitment to carrying out an action of a person in a short or long term.

3. Cognitive component referred to the beliefs, thoughts, and values about the language of learners. Moreover, these attributes and elements that people would associate with an object, concerned the opinion or mental representation segment of an attitude which was related in general knowledge of a person.

\section{Method}

\subsection{Setting and participants}

In this study, a survey was used to collect the data which were gathered from accessible samples of students by a questionnaire at a university in the eastern part of Thailand. As shown in Table 1, a total number of 330 students 
(222 females, 108 males) filled out the questionnaires. All of the Thai university students were older than 18 years (average age of 20.02, ranging from 18 to 25). Among the groups, the participants at the age of 19 and 20 had the first and second highest number. The group consisted of freshmen $(N=59,17.9 \%)$, sophomores $(N=195,59.1 \%)$, juniors $(N=44,13.3 \%)$, and seniors $(N=32,9.7 \%)$. Among the grades, the participants from sophomore had the highest number. In respect to major, participants studied English Language and Literature from Faculty of Humanities and Social Sciences $(N=150,45 \%)$, and English for business and commerce from International College $(N=180,55 \%)$. Participants started learning English from 3 years old (average age of 5.02, ranging from 3 to 13). Among the groups, the participants at the age of 5 years old had the highest number $(N=110,33.3 \%)$. A total number of 153 participants who ever had international experience (46.4\%). Among them, 132 students who had the experience less than one year $(N=132,40 \%)$ and 21 students who had not the experience more than one year $(N=21,6.4 \%)$. A total number of 270 participants who had the experience of learning English with American $(N=270,81.8 \%)$. Among them, the students who started English with native-speakers at high school stage had the highest number $(N=120,36.4 \%)$. The group consisted of the participants whose parents can speak English $(N$ $=87,26.4 \%)$ and who cannot $(N=243,73.6 \%)$.

Table 1: Demographic Characteristics of the Participants

\begin{tabular}{|c|c|c|}
\hline Demographic Characteristics & Frequency & Percentage \\
\hline Male & 108 & 32.7 \\
\hline Female & 222 & 67.3 \\
\hline \multicolumn{3}{|l|}{ Age } \\
\hline 18.00 & 7 & 2.1 \\
\hline 19.00 & 113 & 34.2 \\
\hline 20.00 & 125 & 37.9 \\
\hline 21.00 & 48 & 14.5 \\
\hline 22.00 & 30 & 9.1 \\
\hline 23.00 & 4 & 1.2 \\
\hline 24.00 & 2 & .6 \\
\hline 25.00 & 1 & .3 \\
\hline \multicolumn{3}{|l|}{ Grades } \\
\hline Freshmen & 59 & 17.9 \\
\hline Sophomores & 195 & 59.1 \\
\hline Juniors & 44 & 13.3 \\
\hline Seniors & 32 & 9.7 \\
\hline \multicolumn{3}{|l|}{ Major } \\
\hline FH & 150 & 45 \\
\hline $\mathrm{IC}$ & 180 & 55 \\
\hline \multicolumn{3}{|l|}{ Starting age } \\
\hline 3.00 & 71 & 21.5 \\
\hline 4.00 & 57 & 17.3 \\
\hline 5.00 & 110 & 33.3 \\
\hline 6.00 & 32 & 9.7 \\
\hline 7.00 & 42 & 12.7 \\
\hline 8.00 & 5 & 1.5 \\
\hline 9.00 & 1 & .3 \\
\hline 10.00 & 7 & 2.1 \\
\hline 11.00 & 2 & .6 \\
\hline 12.00 & 2 & .6 \\
\hline 13.00 & 1 & .3 \\
\hline \multicolumn{3}{|l|}{ International Experience } \\
\hline Yes & 153 & 46.4 \\
\hline No & 177 & 53.6 \\
\hline Less than one year & 132 & 40.0 \\
\hline More than one year & 21 & 6.4 \\
\hline
\end{tabular}

Learn English with NS \& since when

American

British

Others

Primary school

Secondary school
3.6

16.1

11.8 


\begin{tabular}{|c|c|c|}
\hline $\begin{array}{l}\text { High school } \\
\text { College/University }\end{array}$ & $\begin{array}{l}120 \\
118\end{array}$ & $\begin{array}{l}36.4 \\
35.8\end{array}$ \\
\hline \multicolumn{3}{|c|}{$\begin{array}{l}\text { Students whose parents can speak English or } \\
\text { not }\end{array}$} \\
\hline Yes & 87 & 26.4 \\
\hline No & 243 & 73.6 \\
\hline \multicolumn{3}{|c|}{$\begin{array}{l}\text { Students whose friends are NS and those are } \\
\text { not }\end{array}$} \\
\hline Yes & 129 & 39.1 \\
\hline No & 201 & 60.9 \\
\hline
\end{tabular}

\subsection{Instrument}

The questionnaire consisted of two parts. The first section was designed to obtain participants' demographic data, such as sex, age, grade, major, starting age of learning English, mother tongue, international experience (IE), learned English with NS (Native Speakers) and since when, whether parents can speak English or not, and friends whose mother tongue is English or not. The second section was divided into three components: affective, behavioral, and cognitive. By using IBM SPSS Statistics Base 22 program, this part was designed to investigate the language attitudes toward Global Englishes among these Thai undergraduate students, and the participants were asked to rate five Likert scale of agreement, there were: $5=$ strongly agree, $4=$ slightly agree, $3=$ agree, $2=$ slightly disagree, 1 = strongly disagree

\subsection{Reliability}

A pilot study was applied to check the reliability of the questionnaire. The objective of the pilot study was to check the items in the questionnaire, decided the survey time, got relevant information from the participants, picked out confounding implications before they would be used to lead the fundamental study. The pilot study process was implemented with 14 undergraduate students at the university during the summer session, 2019. Seven students came from Faculty of Humanities and Social Sciences, and the other seven came from International College. The Cronbach's alpha reliability coefficient was at .76 .

\subsection{Data Collection}

After approval from the Institutional Board Review Board (IRB) had been obtained, the participants were informed of the nature of the present study such as purpose, procedure, benefits, risks, and so on. Then all of the participants were asked for volunteers to take part in the survey. After receiving the permission of the deans of Faculty of Humanities and Social Sciences and International College, I asked for help from a faculty secretary to administer the questionnaire to the target students. I left the questionnaire for two weeks, and I later collected them back. The questionnaire was completed in August 2019.

\subsection{Data analysis}

Data analysis was in a quantitative method, following two steps. Firstly, to address RQ1, the descriptive statistics (i.e. mean $[M]$, standard deviation $[S D]$, skewness, and kurtosis) were calculated and used as reference values for determining considerable normality. Secondly, to address RQ 2 to RQ 5, an independent samples t-test was conducted to investigate the students' statistically different attitudes toward Global Englishes between males and females, different students' majors, different students' IE (International Experience), different students' parents' English ability. However, before performing the t-test, assumptions of normality, homogeneity of variance, and independence of observation were also explored.

\section{Results}

5.1 Participants' Attitudes toward Global Englishes

With regard to research questions, the descriptive statistics results were interpreted as the following:

If the score was between 1 to 1.25 , that was called a Strongly Disagree (SD)

If the score was between 1.26 to 2.51 , that was called a Disagree (D)

If the score was between 2.52 to 3.77, that was called a Agree (A)

If the score was between 3.50 to 4.49 , that was called a Strongly Agree (SA)

Before performing the inferential statistics, the assumptions of independent $t$-test were performed as shown below: 

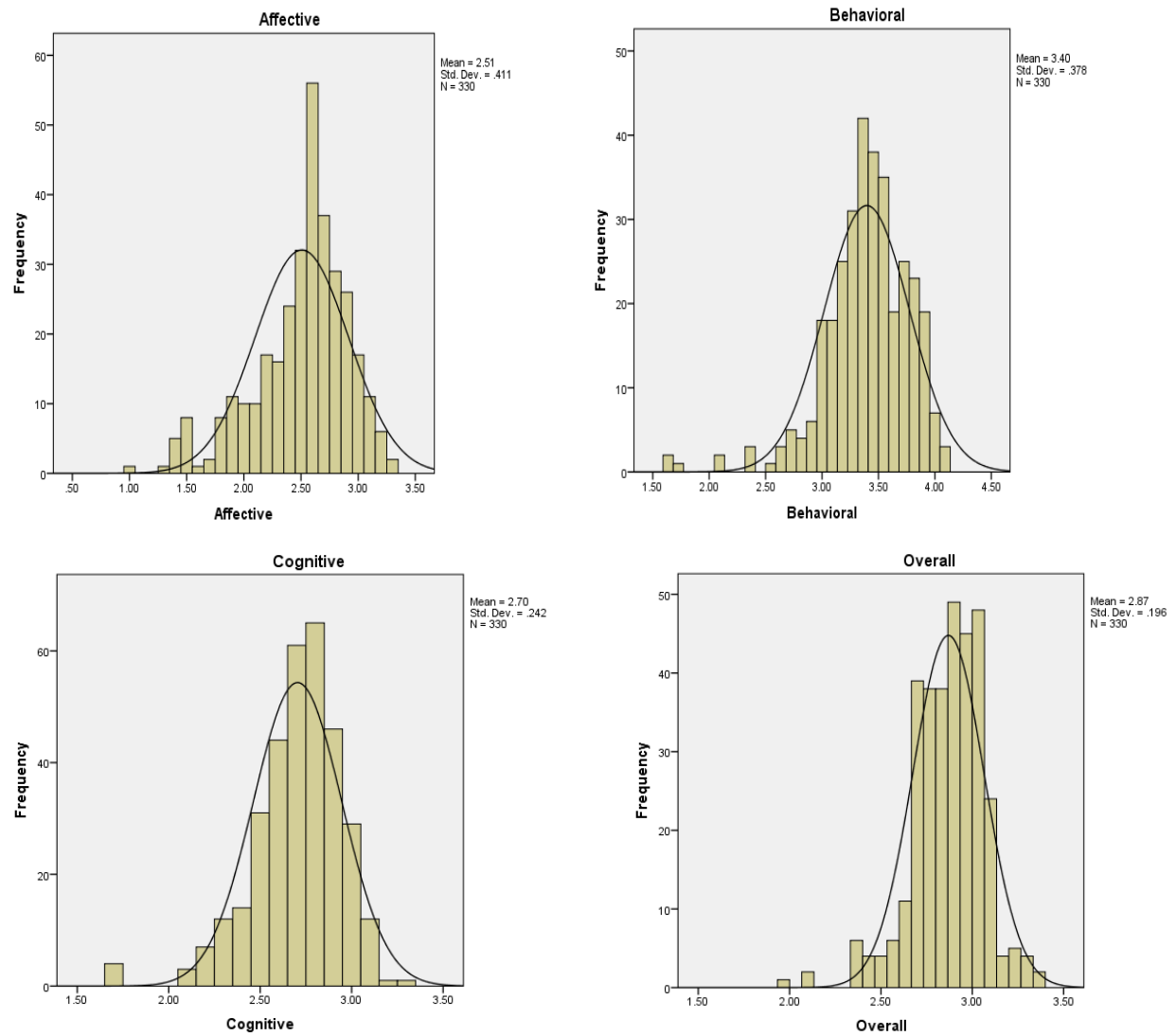

Figure 1 Histograms of Attitudes Toward Global Englishes

According to Mishra (2019), for small sample size $(\mathrm{n}<50), z$ value \pm 1.96 are sufficient to establish normality of the data. However, medium-sized samples $(50 \leq n<300)$, at absolute $z^{-}$value \pm 3.29 , conclude the distribution of the sample is normal. For sample size $>300$, normality of the data is depended on the histograms and the absolute values of skewness and kurtosis. Either an absolute skewness value $\leq 2$ or an absolute kurtosis (excess) $\leq 4$ may be used as reference values for determining considerable normality.

Table 2: Descriptive statistics of Skewness and Kurtosis

\begin{tabular}{|c|c|c|c|c|c|}
\hline & & Affective & Behavioral & Cognitive & Overall \\
\hline \multirow[t]{2}{*}{$\mathrm{N}$} & Valid & 330 & 330 & 330 & 330 \\
\hline & Missing & 0 & 0 & 0 & 0 \\
\hline \multicolumn{2}{|c|}{ Mean } & 2.51 & 3.40 & 2.70 & 2.87 \\
\hline \multicolumn{2}{|c|}{ Std. Deviation } & .41 & .38 & .24 & .20 \\
\hline \multicolumn{2}{|c|}{ Skewness } & -.88 & -1.25 & -1.05 & -.84 \\
\hline \multicolumn{2}{|c|}{ Std. Error of Skewness } & .13 & .13 & .13 & .13 \\
\hline \multicolumn{2}{|c|}{ Kurtosis } & .74 & 3.67 & 2.54 & 2.04 \\
\hline \multicolumn{2}{|c|}{ Std. Error of Kurtosis } & .27 & .27 & .27 & .27 \\
\hline
\end{tabular}

As shown in Table 2, the average affective component of students' attitudes toward Global Englishes was $2.51(S D=0.41)$, with skewness of $-0.88(S E=0.13)$ and kurtosis of $0.71(S E=0.27)$. The average behavioral component of students' attitudes toward Global Englishes was $3.40(S D=0.38)$, with skewness of $-1.25(S E=$ $0.13)$ and kurtosis of $3.67(S D=0.27)$. The average cognitive component of students' attitudes toward Global Englishes was $2.70(S D=0.24)$, with skewness of $-1.05(S E=0.13)$ and kurtosis of $2.54(S E=0.27)$. The overall component of students' attitudes toward Global Englishes was $2.87(S D=0.20)$, with skewness of $-0.84(S E=$ $0.13)$ and kurtosis of $2.04(S E=0.27)$. All data could be used as reference values for determining considerable normality.

As shown in Figure 1, based on histograms, it could be concluded that all data were normal. Therefore, it was legitimate to run the $t$-test. This section reported the answers to the research questions by using descriptive statistics. Before running the Independent $t$-test, histograms were used to determine the normality of the data.

5.2 Findings of Research Question 1: What were the learners' attitudes toward Global Englishes?

This question reported the answers to the first question by using descriptive statistics. The means and standard deviations were reported to measure the categories of these relevant participants' attitudes toward Global Englishes. 
Table 3: Descriptive statistics of students' attitudes toward Global Englihes

\begin{tabular}{lcc}
\hline & & $\boldsymbol{N}=\mathbf{3 3 0}$ \\
\cline { 2 - 3 } Categories & $\boldsymbol{M}$ & $\boldsymbol{S D}$ \\
\hline Affective & 2.51 & 0.41 \\
Behavioral & 3.40 & 0.38 \\
Cognitive & 2.70 & 0.24 \\
\hline Total & $\mathbf{2 . 8 7}$ & $\mathbf{0 . 2 0}$ \\
\hline
\end{tabular}

As shown in Table 3, the data indicated that the participants held medium attitudes toward Global Englishes $(M=2.87, S D=0.20)$. Specifically, compared to the other two categories: the affective $(M=2.51, S D=0.41)$ and the cognitive $(M=2.70, S D=0.24)$; the category of behavioral $(M=3.40, S D=0.38)$ scored the highest, which indicated that these participants held medium attitudes toward Global Englishes on behavioral component.

\subsection{Findings of Research question 2: Were there any statistically different attitudes toward Global Englishes} between male and female students?

Based on the histograms, it was revealed that all data were normal. Therefore, it was legitimate to run the $t$-test. This section reports the answers to the second research question by using an independent $t$-test as indicated in Table 4.

Table 4: Comparison of attitudes toward Global Englishes between males and females

\begin{tabular}{llccccc}
\hline & Gender & $\boldsymbol{t}$ & $\boldsymbol{d} \boldsymbol{f}$ & $\boldsymbol{M}$ & $\boldsymbol{S D}$ & $\boldsymbol{S i g}$ \\
\hline Affective & Male & -1.20 & 328 & 2.46 & 0.47 & .23 \\
Behavioral & Female & & & 2.52 & 0.37 & \\
& Male & 1.40 & 328 & 3.43 & 0.34 & .16 \\
Cognitive & Female & & & 3.37 & 0.39 & \\
& Male & 0.60 & 328 & 2.71 & 0.22 & .55 \\
Overall & Female & & & 2.69 & 0.24 & \multirow{2}{*}{.76} \\
& Male & 0.31 & 328 & 2.87 & 0.18 & \\
\hline
\end{tabular}

$$
* \mathrm{p}<.05
$$

To answer the research question regarding gender differences in perceptions of faculty mentoring, an independent samples t-test was used. The test was conducted at an alpha of .05. Table 4 presented the comparison of statistically different attitudes toward Global Englishes between male and female students. For affective component, there was not a significant difference for males $(M=2.46, S D=0.47)$ and females $(M=2.52, S D=$ $0.37) ; t(328)=-1.20, p=0.23$. For behavioral component, there was not a significant difference for males $(M=$ $3.43, S D=0.34)$ and females $(M=3.37, S D=0.39) ; t(328)=1.40, p=0.16$. For cognitive component, there was not a significant difference for males $(M=2.71, S D=0.22)$ and females $(M=2.69, S D=0.24) ; t(328)=0.60, p$ $=0.55$. For overall, there was not a significant difference for males $(M=2.87, S D=0.18)$ and females $(M=2.86$, $S D=0.20) ; t(328)=0.31, p=0.76$.

5.4 Findings of Research Question 3: Were there any statistically different attitudes toward Global Englishes between Faculty of Humanities and Social Sciences and International College students?

Based on the histograms, it was revealed that all data were normal. Therefore, it was legitimate to run the $t$-test. This section reports the answers to the third research question by using an independent $t$-test as indicated in Table 5 .

Table 5: Comparison of attitudes toward Global Englishes about different majors

\begin{tabular}{|c|c|c|c|c|c|c|}
\hline & Major & $t$ & $d f$ & $M$ & $S D$ & Sig \\
\hline \multirow[t]{2}{*}{ Affective } & $\mathrm{FH}$ & 1.46 & 328 & 2.54 & 0.36 & .15 \\
\hline & IC & & & 2.47 & 0.44 & \\
\hline \multirow[t]{2}{*}{ Behavioral } & FH & -2.45 & 328 & 3.34 & 0.43 & $.02 *$ \\
\hline & IC & & & 3.44 & 0.31 & \\
\hline \multirow[t]{2}{*}{ Cognitive } & FH & -4.58 & 328 & 2.63 & 0.28 & $.00 *$ \\
\hline & IC & & & 2.75 & 0.18 & \\
\hline \multirow[t]{2}{*}{ Overall } & FH & -2.40 & 328 & 2.84 & 0.23 & $.02 *$ \\
\hline & $\mathrm{IC}$ & & & 2.89 & 0.15 & \\
\hline
\end{tabular}

$* \mathrm{p}<.05$

To answer the research question regarding different majors in perceptions of faculty mentoring, an independent samples t-test was used. The test was conducted at an alpha of .05 . Table 5 presented statistically different students' attitudes toward Global Englishes between different majors form the two faculties. For overall, it was revealed that there was a significant difference between FH $(M=2.84, S D=0.23)$ and $\mathrm{IC}(M=2.89, S D=$ 
$0.15) ; t(328)=-2.39, p=0.02$. For affective component, there was not a significant difference between FH $(M=$ $2.54, S D=0.36)$ and IC $(M=2.47, S D=0.44) ; t(328)=1.46, p=0.15$. For behavioral component, there was a significant difference between FH $(M=3.34, S D=0.43)$ and IC $(M=3.44, \mathrm{SD}=0.31) ; t(328)=-2.45, p=0.02$. For cognitive component, there was a significant difference between FH $(M=2.63, S D=0.28)$ and $\mathrm{IC}(M=2.75$, $S D=0.18) ; t(328)=-4.58, p=0.00$.

5.5 Findings of Research Question 4: Were there any different attitudes toward Global Englishes between students who had international experience and those who did not have?

Based on the histograms, it was revealed that all data were normal. Therefore, it was legitimate to run the $t$-test. This section reports the answers to the fourth research question by using an independent $t$-test as indicated in Table 6.

Table 6: Comparison of attitudes toward Global Englishes between students who had IE (International Experience) and those had not

\begin{tabular}{llccccc}
\hline & IE & $\boldsymbol{t}$ & $\boldsymbol{d} \boldsymbol{f}$ & $\boldsymbol{M}$ & $\boldsymbol{S D}$ & Sig \\
\hline Affective & Yes & -1.08 & 328 & 2.48 & 0.44 & .28 \\
& No & & & 2.52 & 0.37 & \\
Behavioral & Yes & 1.19 & 328 & 3.42 & 0.32 & .23 \\
& No & & & 3.37 & 0.41 & \\
Cognitive & Yes & 3.79 & 328 & 2.75 & 0.18 & $.00^{*}$ \\
& No & & & 2.65 & 0.27 & \\
Overall & Yes & 1.55 & 328 & 2.88 & 0.16 & .12 \\
& No & & & 2.85 & 0.22 & \\
\hline
\end{tabular}

$* p<.05$

To answer the research question regarding international experience differences in perceptions of faculty mentoring, an independent samples t-test was used. The test was conducted at an alpha of .05. Table 6 presented statistically different students' attitudes toward Global Englishes about their international experience. For overall, there was not a significant difference between "Students had IE" $(M=2.88, S D=0.16)$ and "Students did not have IE" $(M=2.85, S D=0.22) ; t(328)=1.55, p=0.12$. For affective component, there was not a significant difference between "Students had IE" $(M=2.48, S D=0.44)$ and "Students did not have IE" $(M=2.52, S D=0.37) ; t(328)$ $=-1.08, p=0.28$. For behavioral component, there was not a significant difference between "Students had IE" $(M$ $=3.42, S D=0.32)$ and "Students did not have IE" $(M=3.37, S D=0.41) ; t(328)=1.19, p=0.23$. For cognitive component, there was a significant difference between "Students had IE" $(M=2.75, S D=0.18)$ and "Students did not have IE" $(M=2.65, S D=0.27) ; t(328)=3.79$.

5.6 Findings of Research Question 5: Were there any statistically different attitudes toward Global Englishes between students' parents who can speak English and those who cannot?

Based on the histograms, it was revealed that all data were normal. Therefore, it was legitimate to run the $t$-test. This section reports the answers to the second research question by using an independent $t$-test as indicated in Table 7.

Table 7: Comparison of attitudes toward Global Englishes between students' parents who can speak English and those cannot

\begin{tabular}{llccccc}
\hline & Parents can speak English & $\boldsymbol{t}$ & $\boldsymbol{d f}$ & $\boldsymbol{M}$ & $\boldsymbol{S D}$ & \multicolumn{1}{c}{ Sig } \\
\hline Affective & Yes & 2.85 & 328 & 2.61 & 0.34 & $.01^{*}$ \\
& No & & & 2.46 & 0.42 & \\
Behavioral & Yes & -1.83 & 328 & 3.33 & 0.41 & .06 \\
& No & & & 3.42 & 0.36 & \\
Cognitive & Yes & -0.04 & 328 & 2.70 & 0.25 & .97 \\
& No & & & 2.70 & 0.23 & \\
Overall & Yes & \multirow{2}{*}{0.76} & 328 & 2.88 & 0.21 & .45 \\
& No & & & 2.86 & 0.18 & \\
\hline
\end{tabular}

$$
* \mathrm{p}<.05
$$

To answer the research question regarding the "Parents' backgrounds" differences in perceptions of faculty mentoring, an independent samples t-test was used. The test was conducted at an alpha of .05. Table 7 presented the different attitudes toward Global Englishes between students' parents who can speak English and those cannot. For overall, there was not a significant difference between "Parents can" $(M=2.88, S D=0.21)$ and "Parents cannot" $(M=2.86, S D=0.18) ; t(328)=0.76, p=0.45$. For affective component, there was a significant difference between "Parents can" $(M=2.61, S D=0.34)$ and "Parents cannot" $(M=2.46, S D=0.42) ; t(328)=2.85, p=0.01$. For behavioral component, there was not a significant difference between "Parents can" $(M=3.33, S D=0.41)$ and "Parents cannot" $(M=3.42, S D=0.46) ; t(328)=-1.87, p=0.06$. For cognitive component, there was not a 
significant difference between "Parents can" $(M=2.70, S D=0.25)$ and "Parents cannot" $(M=2.70, S D=0.23) ; t$ $(328)=-0.04, p=0.45$.

\section{Discussion}

This section provided a discussion of the research findings in the present study which was focused on investigating language attitudes toward Global Englishes among Thai undergraduate students from the two different faculties. And the study attempted to compare students' language attitudes toward Global Englishes across socio-cultural variables, such as sex, major, international experience, and parents' English ability. The following discussion was based on the analysis in the previous studies.

Compared Sung (2015) who used a mixed method and found that the GE (Global Englishes) component seemed to have little impact on changing Hong Kong students' perceptions regarding the superiority of native English speakers and their negative insight of 'non-standard' and/or 'non-native' varieties of English. Although some students claimed that they had the inclination to accept the diversity of different Englishes, including nonnative English varieties, they still regarded some non-native English varieties as containing 'errors' that were in need of remediation. The present study demonstrated the different results that the Thai undergraduate students had an inclination to keep open minds about accepting, speaking and using English or varieties of English.

Compared Mtawaa (2017) who used a mixed method and set out the study to examine male and female Saudi students' attitudes towards English and the attitudes and perceptions of parents on the importance of English. The findings of the study indicate that both students and parents have positive attitudes towards English. Means and standard deviations show that male students have more positive attitudes towards English than their female counterparts. The findings also reveal that parents perceive English positively as the international language of science, technology and business. The results of the present study indicated that there were not any statistically different students' attitudes toward Global Englishes between males and females within the three language attitudes' components.

Compared Lee and Lee (2019) who used a mixed method and set out the study to examine EIL perceptions by Korean English and non-English-major students, also investigated factors that influenced the students' perceptions. These results indicated that an EIL experience that occurred in a formal language classroom could positively influenced students' perceptions. Furthermore, students' engagement in IDLE (Informal Digital Learning of English) activities might also have a significant impact on their perceptions of EIL, even though the teachers' instructional intervention was absent. The present study indicated that the participants from different majors not only had different beliefs and thoughts about Global Englishes, but they also had different inclination to speak and use English or varieties of English.

Compared Bunch, Rampold, Cater and Blackburn (2018) who set out a qualitative method to develop a deep understanding of the lived experiences of agricultural education undergraduate students participating in a shortterm international experience. As a result of the short-term international experience, students did not progress fully through all levels of development needed to be considered proficient in cultural competence. However, students demonstrated significant gains in cultural awareness and some gains in cultural understanding and cultural sensitivity. Finally, participating students verified some progress toward building cultural communication competencies as a result of their experience. The present study indicated that there was a significant difference in cognitive component, and revealed that the participants whose general knowledge about English or varieties of English had been affected by their international experience more or less.

Compared Petchprasert (2014) who used a quantitative method to set out this study in order to investigate parents' backgrounds and their beliefs about English language learning, and compared the receptive English vocabulary development of three- to six-year-old-Thai children before and after participating in a parent-child reading program with the dialogic reading (DR) method. The results showed that parents' beliefs about English language learning affected expectations on their children's language success. In addition, the children's achievement was related to the use of DR method. The children yielded significant greater gains in knowledge of vocabulary and their ability to infer the meanings from pictures after engaging in the reading program. The present study indicated that there was a significant difference in affective component, and revealed that the participants whose emotional or feeling segment was related to their parents' English ability.

In summary, compared with the previous studies, the present study illustrated the important relation between the social-cultural variables (i.e. sex, major, international experience, and parents' English ability) and students' English learning and usage, either. Furthermore, the results of the present study suggested that the Thai undergraduate students held mixed language attitudes toward Global Englishes: on the one hand, some students still wanted to speak or use Standard English and remained their Thai-English at the same time. On the other hand, some students still focused on speaking or using Standard English especially American English all the time. The consequences proved that linguistical hierarchy still existed that American English was still at the top. 


\section{Implications}

This study aimed to generate a better understanding of the students' attitudes toward Global Englishes. In light of the contributions of this study above, the most crucial finding was that the attitudes of the Thai undergraduate students toward Global Englishes were basically Standard English especially American English bound. Their attitudes might be reflections of what they believed as models that they wanted to learn and use. This in turn enhanced their belief that inner circle varieties especially American English was the best model to learn. Furthermore, this understanding was helpful for teachers to plan instruction that aimed to incorporate Global Englishes in the classroom. Without this understanding, teachers might not be able to find ways to help students become aware of the global spread of English and its impact on their English learning.

Some scholars had suggested that increasing exposure of learners to different English varieties could raise their understanding. Also, there needed some important approaches which could raise students' awareness and familiarity with different English varieties so that they can prepare for international communications. More importantly, this study contributed to the current literature on students' attitudes toward Global Englishes. To elaborate, the present study attempted to undertake a new research line, which had not been conducted in previous studies, by comparing attitudes toward Global Englishes across socio-cultural variables, such as sex, major, international experience, and parents' English ability. This understanding contributed to the theoretical discussion on students' attitudes toward Global Englishes.

\section{Recommendation for Future Research}

This study provided limited understanding of Thai undergraduate students' language attitudes toward Global Englishes because of the major limitation in quantitative research was that the study would not get specific details as it might achieve in qualitative research. Nonetheless, the study has generated some new perspectives which deserved further investigation. With respect to these, relevant future research should involve quantitative and qualitative methods and combine them in a mixed method approach in order to capture both aspects of the phenomenon for the purpose of deeper understanding.

\section{References}

Ajzen, I., \& Fishbein, M. (1975). Belief, attitude, intention, and behavior: An introduction to theory and research. Reading, MA: Addison Wesley.

Ajzen, I., \& Fishbein, M. (1980). understanding attitudes and predicting social behavior. Englewood Cliffs, NJ: Prentice-Hall.

Baker, W. (2008). A critical examination of ELT in Thailand: the role of cultural awareness. Regional Language Centre (RELC), 39(1), 131-146.

Baker, W. (2009). The cultures of English as a lingua franca. TESOL Quarterly, 43(4), 567-592.

Baker, W. (2012). English as a Lingua Franca in Thailand: Characterizations and Implications. Englishes in practice issue, $1(5)$. Retrieved from https://www.researchgate.net/publication/271834538_English_as_a_Lingua_Franca_in_Thailand_Character isations_and_Implications

Baker, C. (1992). Attitudes and language. Clevedon, UK: Multilingual Matters.

Bartsch, R. (1987). Norms of languages, theoretical and practical aspects. London, UK: Longman.

Bolton. K. (2006). World Englishes today. In B. B. Kachru, Y. Kachru, \& C. Nelson (Eds.), The handbook of World Englishes (pp. 13-26). Oxford: Wiley-Blackwell.

Brown, K. (2002). Ideology and context: World Englishes and ELF teacher training. World Englishes, 21(3), 445448.

Bunch, J. C., Rampold, S. D., Cater, M., \& Blackburn, J. J. (2018). The impact of a short-term international experience on undergraduate students' cultural competency. Journal of Agricultural Education, 59(4), 120 136.

Butler, Y. G. (2007). How are nonnative-English-speaking teachers perceived by young learners? TESOL Quarterly, 41(4), 731-755.

Canagarajah, S. (2013). Translingual Practice: Global Englishes and cosmopolitan relations. Journal of Sociolinguistics. 19(1), 105-129.

Cheshire, J. (1991). English around the world. Cambridge: Cambridge University Press

Crystal, D. (1997). English as a global language. Cambridge: Cambridge University Press.

Crystal, D. (2003b). English as a global language (2 ${ }^{\text {nd }}$ edition). Cambridge: Cambridge University Press.

Crystal, D. (2006a). English worldwide in R. Hogg \& D. Dension (eds.): A History of the English language. Cambridge: Cambridge University Press.

David, H. (2014). The value of learning English in Thailand and its impact on Thai: perspectives from university students. Asia Pacific Journal of Education, 36(1), 73-91

Davis, J.A. (1971). Elementary survey analysis. Englewood, NJ: Prentice Hall. 
Derbaix, C., \& Pham, M.T. (1991). Affective Reactions to Consumption Situations: A Pilot Investigation. Journal of economic psychology, 12(2), 325-355.

Dewey, M (2007). English as a lingua franca and globalization: an interconnected perspective. International journal of applied linguistics, 17(3), 332-354.

Dörnyei, Z. (2009). The psychology of second language acquisition. Oxford: Oxford University Press

Eagly, A.H., \& Chaiken, S. (1993). The psychology of attitudes. Fort Worth, TX: Harcourt Brace Jovanovich College Publishers.

Ellis, R. (1997). Second language acquisition. Oxford: Oxford University Press.

Erdfelder, E., Faul, F., \& Buchner, A. (1996). GPOWER: A general power analysis program. Behavior Research Methods, Instruments, \& Computers, 28(1), 1-11.

Fishman, J.A., \& A. Rubal-Lopez. (1992). Cross-policy analysis of factors affecting English language spread: Predicting three criteria of spread from a large pool of independent variables. World Englishes, 11(2), 309329.

Foley, J. (2007). English as a global language: my two Satangs' worth. RELC, 38(1), 7-17.

Friedrich, P. (2000). English in Brazil: functions and attitudes, World Englishes, 19(2), 215-223.

Galloway, N. \& Rose, H. (2015). Global Englishes. London: Routledge

Garrett, P. (2001). Language attitudes and sociolinguistics. Journal of Sociolinguistics 5(4), 626-631.

Garrett, Peter. (2010). Attitudes to language. Cambridge: Cambridge University Press.

George, D., \& Mallery, P. (2003). SPSS for Windows step by step: A simple guide and reference. 11.0 update ( $4^{\text {th }}$ ed.). Boston: Allyn \& Bacon.

Graham, H. (2016). The Routledge handbook of English language teaching. London: Routledge

Groves, R. M., Fowler, F. J., Couper, M. P., Lepkowski, J. M., Singer, E., \& Tourangeau, R. (2009). Survey methodology (2nd ed.). Wiley: Hoboken, N.J.

Havitz, M. E., \& Dimanche, F. (1999). Leisure Involvement Revisited: Drive Properties and Paradoxes. Journal of leisure research, 31(2), 122-149.

Heather T. Rowan-Kenyon \& Elizabeth K. Niehaus (2011). One year later: The influence of short-term study abroad experiences on students. Journal of Student Affairs Research and Practice, Volume 48: Issue 2, 213228.

Hogg, M., \& Vaughan, G. (2005). Social psychology (4th edition). London: Prentice-Hall.

Horley, J., and Little, B.R. (1985). Affective and Cognitive Components of Global Subjective Well-Being Measures. Social Indicators Research, 17(2): 189-197.

Irvine, J. (1989). When talk isn't cheap: Language and political economy. American Ethnologist, 16(2), 248-267.

Jenkins, J. (2006a). Current perspective on teaching world Englishes and English as a lingua franca. TESOL Quarterly, 40(1),157-181.

Jenkins, J. (2009). World Englishes: A resource for students ( $2^{\text {nd }}$ ed.). London: Routledge.

Kachi, R. (2004). Factors predicting native and nonnative listeners' evaluative reactions to Japanese English. Columbus, Ohio: Ohio State University Press

Kachru, B. B. (1992). The other tongue (2 ${ }^{\text {nd }}$ ed.). Urbana, IL: University of Illinois Press

Kachru, B. B. (1996). World Englishes: Agony and ecstasy. Journal of aesthetic Education, 30(2), 135-155.

Kirkpatrick, A. (2007). Setting attainable and appropriate English language targets in multilingual settings: a case for Hong Kong. International journal of applied linguistics, 17(3), 376-391.

Kirkpatrick, A. (2010). English as a lingua franca in ASEAN. Hong Kong: Hong Kong University Press.

Krejcie \& D. W. M. (1970). Determining Sample Size for Research Activities. Educational and Psychological Measurement, 30, 607-610.

Lee, J. S. and Lee, K. (2019). Perceptions of English as an international language by Korean English-major and non-English-major students. Journal of Multilingual and Multicultural Development, 40(1), 76-89.

Linda, Melander (2003). Language attitudes-evolutional reactions to spoken language. School of Languages and Media Studies. Högskolan Dalarna.

Lindemann, S. (2003). Koreans, Chinese or Indians? Attitudes and ideologies about non-native English speakers in the United States. Journal of sociolinguistics 7(3), 348-364.

MacKenzie, S. B., \& Lutz, R. J. (1989). Information Processing from Advertisements: Toward an Integrative Framework. Journal of Marketing, 53(4), 1-23.

Maiken Risan (2014). Fake it till you make it - attitudes towards L2 accents among prospective English teachers in Norway. Master's Thesis in English Sociolinguistics Department of Language and Literature Faculty of Humanities NTNU. Trondheim.

Martin A. Kayman (2004). The state of English as a global language: communicating culture. Textual Practice, $18(1), 1-22$.

Matsuda, A. (2000). Japanese attitudes toward English: a case study of high school students. Unpublished doctoral dissertation, Purdue University, West Lafayette, Indiana. 
Matsuda, A. (2002). International understanding through teaching world Englishes. World Englishes, 21(3), 436440.

Matsuda, A. (2003). Incorporating world Englishes in teaching English as an international language. TESOL Quarterly, 37(4), 719-729.

Mauranen, A. (2003). The Corpus of English as Lingua Franca in Academic Settings. TESOL Quarterly 37(3), 513-527.

McArthur, Tom (2012). English world-wide in the twentieth century. In Lynda Mugglestone. The Oxford history of English. $2^{\text {nd }}$ ed., 446-487. Oxford: Oxford University Press.

McIntyre, D. (2009). A history of English: a resource book for students. London: Routledge

McKenzie, R. M. (2003). Attitudes of Japanese nationals' resident in Scotland towards standard and non-standard varieties of English. Saga University Economic Review 35(5/6), 137-150.

McKenzie, R. M. (2016). The social psychology of English as a global language: attitudes, awareness and identity in the Japanese context. English Language and Linguistics, Northumbria University, Lipman Building, Sandyford Road Newcastle Upon Tyne, NE1 8ST, United Kingdom.

Mckay, S.L. (2000). Teaching English as an international language. Oxford: Oxford University Press.

McLeod, S. A. (2018). Attitudes and behavior. SimplyPsychology. Retrieved from https://www.simplypsychology.org/attitudes.html

Melchers, G. \& Shaw, P. (2011). World Englishes (2nd ed). London: Hodder

Melitz, Marc J. (2007). The impact of trade on intra-industry reallocations and aggregate industry productivity. Econometrica, 71(6). 1695-1725.

Mtawaa, J. B. Y. (2017). Examining the impact of gender and students' parents on attitudes towards English: The case of Saudi Arab students and their parents in Al-Kamel College of Science and Arts. International journal of social science and humanity, Vol. 7, No. 4.

Nettle, D. and Romaine, S. (2000). Vanishing voices. Oxford: Oxford University Press

Obiols, M. S. (2002). The matched guise technique: A critical approximation to a classic test for formal measurement of language attitudes. Retrieved from https://www.semanticscholar.org/paper/The-MatchedGuise-Technique\%3A-a-Critical-to-a-Test-Obiols/84a46f18d972850ee8e9736a42737975417bceae

Oppenheim, A. N. (1992). Questionnaire design, interviewing and attitude measurement. London: Continuum.

Rao, P. S. (2019). The role of English as a global language. Research journal of English (RJOE), Vol-4, Issue-1.

Robert M. M., Patchanok K., \& Phaisit B. (2016). The competence and warmth of Thai students' attitudes towards varieties of English: The effect of gender and perceptions of L1 diversity. Journal of Multilingual and Multicultural Development, 37(6), 536-550.

Ryan, E. B. \& Giles, H. (1982). Attitudes towards language variation. Edward Arnold. London.

Sandra, M. (2002). Teaching English as an international language. Oxford: Oxford University Press.

Samarin, W. (1987). Lingua Franca. Ammom, U. N. \& Mattheier. K. (Eds.). Sociolinguistics: An international handbook of the science of language and society (pp. 371-374). Berlin: Walter de Gruyter

Saxena, Mukul \& Omoniyi, T. (2010). Globalization \& World Englishes. Clevedon, Bristol, England: Channel View Publications.

Schneider, Edgar W. (2007). Postcolonial English-varieties around the world. Cambridge: Cambridge University Press

Seidlhofer, B. (2001). Closing a conceptual gap: the case for a description of English as a lingua franca. International journal of applied linguistics, 11(2), 133-158.

Seidlhofer, B. (2005). English as a lingua franca. ELT journal, 59(4), 339-341

Seidlhofer, B. (2011). Understanding English as a Lingua Franca. Oxford: Oxford University Press.

Simmons, C. J., \& Lynch, J. G. (1991). Inference effects without inference making: Effects of missing information on discounting and use of presented information. Journal of consumer research, 17(4), 477-491.

Snow, D. (2007). Sustaining self-directed language learning in the Chinese context. In J. Liu (Ed), English language teaching in China (pp.211-230). London: Continuum International Publishing Group.

Timmis, I. (2002). Native-speaker norms and international English: a classroom view. ELT Journal, 56(3), 240249

Vogt, W.P. (1999). Dictionary of statistics \& methodology: A nontechnical guide for the social science. Thousand Oaks, CA: Sage Publications.

Young, M (2006). Macro students' attitudes toward English: A post-1999 survey. World Englishes, 25(34), 479490. 